\title{
Atrial fibrillation is associated with a lower exercise capacity in male chronic heart failure patients
}

\author{
K Pardaens, J Van Cleemput, J Vanhaecke, R H Fagard
}

\begin{abstract}
Objective-To study the influence of atrial fibrillation on peak oxygen uptake (peak $\left.\dot{V} O_{2}\right)$ in chronic heart failure. An unfavourable effect of atrial fibrillation has been shown in several patient populations, but the results have not been consistent in chronic heart failure.

Methods-Data were analysed from male heart transplant candidates who were able to perform graded bicycle ergometry until exhaustion with respiratory gas analysis and measurement of heart rate. Patients in atrial fibrillation $(n=18)$ were compared with patients in sinus rhythm (n = 93).
\end{abstract}

Results-Age, weight, height, and aetiology of chronic heart failure did not differ significantly between the two groups. Cardiac catheterisation at supine rest showed that heart rate was comparable, but that stroke volume and cardiac output were lower $(p<0.05)$ in atrial fibrillation. Systolic and diastolic left ventricular function, assessed by radionuclide angiography at rest, were not significantly

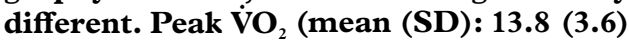
$v 17.1(5.6) \mathrm{ml} / \mathrm{kg} / \mathrm{min} ; \mathrm{p}<0.01)$ and peak work load $(78(27) v 98(36) \mathrm{W}$; p $<0.05)$ were lower in the patients with atrial fibrillation, though respiratory gas exchange ratio and Borg score were similar in the two groups. Patients with atrial fibrillation had a higher heart rate sitting at rest before exercise (93 (16) $v 84$ (16) beats/min) and at peak effort (156 (23) $v$ 140 (25) beats/min) $(p<0.05)$.

Conclusions-Atrial fibrillation is associated with a $20 \%$ lower peak $\dot{V}_{2}$ in patients with chronic heart failure, suggesting that preserved atrial contraction or a regular rhythm, or both, are critical to maintain cardiac output and exercise performance. (Heart 1997;78:564-568)

Keywords: peak oxygen uptake; exercise capacity; chronic heart failure; atrial fibrillation

Easy fatiguability is a frequent complaint of patients in atrial fibrillation ${ }^{1}$ and a lower exercise tolerance has been observed in several reports. ${ }^{2-9}$ One study has shown that exercise capacity in patients with "lone atrial fibrillation", that is, atrial fibrillation without underlying heart disease, is less than in healthy sex and age matched controls. ${ }^{3}$ Many investigators have shown the unfavourable influence of atrial fibrillation by comparing peak oxygen uptake $\left(\dot{\mathrm{VO}}_{2}\right)$ before and after cardioversion to sinus rhythm. ${ }^{24-9}$ These studies mainly examined patients in whom atrial fibrillation was present as a result of mild cardiovascular diseases (New York Heart Association class I or II). Patients with advanced heart failure were either excluded or poorly represented. To the best of our knowledge, only one report has focused on patients with moderate to severe heart failure. ${ }^{10}$ Surprisingly, in this report peak $\mathrm{VO}_{2}$ of patients in atrial fibrillation did not differ significantly from that of patients in sinus rhythm. The possible mechanisms by which atrial fibrillation might influence exercise capacity have not been elucidated. The importance of the atrial kick to left ventricular filling may depend on several factors such as age ${ }^{11}$ and cardiac status, ${ }^{12}$ and may be different at rest and during exercise. ${ }^{13} 14$ In addition, the loss of a regular sinus rhythm may further compromise cardiac output. ${ }^{15}$

The present analysis was performed in view of the paucity of studies with regard to the impact of atrial fibrillation on exercise capacity of patients with advanced heart failure. Atrial fibrillation is a common finding in the setting of chronic heart failure and exercise testing is frequently performed in these patients. Indeed, peak $\mathrm{VO}_{2}$ is a powerful prognostic index and plays an important role in the decision making for heart transplantation. ${ }^{16}$ Further, aerobic power or peak $\dot{\mathrm{VO}}_{2}$ is widely accepted as the gold standard of exercise capacity, and this includes patients with chronic heart failure. ${ }^{17} 18$ The primary aim of our study was to examine whether loss of atrial contraction is associated with a reduction in aerobic power. We hypothesised that atrial fibrillation influences cardiac haemodynamics and therefore peak $\dot{\mathrm{VO}}_{2}$.

\section{Methods}

STUDY POPULATION

From a cohort of 243 patients with heart failure who had been referred to the University Hospital of Leuven for a pre-heart transplant work up between May 1991 and November 1995, 111 patients were selected post hoc for the present analysis. Women $(n=55)$ were not included, to rule out the possible effect of gender on exercise performance and because of their relatively small number. Male patients $(\geqslant 18$ years) were eligible if they were able to exercise until voluntary fatigue. Patients were excluded if one or more of the following conditions was present: heart failure due to primary 
pulmonary hypertension, valvar deficits, or congenital heart disease $(n=9)$; an artificial pacemaker or atrial flutter $(n=17)$; premature interruption of the exercise test for other reasons but dyspnoea, general fatigue, or leg fatigue ( $n=33$ ); and limitation of exercise performance by associated locomotor or pulmonary diseases $(n=34)$.

As part of the pre-heart transplant work up, all patients performed upright bicycle ergometry. The majority of patients included in the present analysis also underwent cardiac catheterisation and radionuclide angiography at rest during the same hospital stay. All patients gave oral informed consent.

\section{EXERCISE TESTING}

All patients performed maximum bicycle ergometry when they were clinically stable. Drug treatment was not interrupted on the day of the test.

The exercise test always took place between 0900 and 1230 . The patient remained seated on the bicycle for two minutes or more and then started cycling at a work load of $10 \mathrm{~W}$. The load was increased by $10 \mathrm{~W}$ per minute until exhaustion. At rest and during exercise, $\dot{\mathrm{VO}}_{2}$ and carbon dioxide output were measured continuously (Sensormedics 2900). After collection of the expired air in a mixing box, minute ventilation was determined by a pneumotachograph; a paramagnetic and an infrared gas analyser, respectively, were used to measure oxygen and carbon dioxide concentrations. Subsequently, $\dot{\mathrm{VO}}_{2}$ and carbon dioxide output were reduced to standard temperature $\left(0^{\circ} \mathrm{C}\right)$ and pressure $(760 \mathrm{~mm} \mathrm{Hg}$ ), dry (STPD) conditions. Each morning the gas analysers were calibrated with precise gas mixtures, and the pneumotachograph with a fixed volume calibration pump. Peak $\mathrm{VO}_{2}$ was defined as the highest $\dot{\mathrm{VO}}_{2}$ during any stage that could be sustained for one minute, which in most instances corresponded to the highest work load that was sustained for one minute. The respiratory gas exchange ratio was calculated as carbon dioxide output divided by $\mathrm{VO}_{2}$; the peak respiratory gas exchange ratio was defined as the highest value over any 20 second period at the end of exercise. The peak oxygen pulse was obtained by dividing the $\dot{\mathrm{VO}}_{2}$ during the highest work load that could be sustained for one minute by the corresponding heart rate, and was also expressed in $\mathrm{ml} / \mathrm{beat} / \mathrm{m}^{2}$ by first dividing $\dot{\mathrm{VO}}_{2}$ by body surface area. Minute ventilation, the ventilatory equivalents for oxygen (calculated as minute ventilation divided by $\dot{\mathrm{V}}_{2}$ ) and carbon dioxide (calculated as minute ventilation divided by carbon dioxide output) at this exercise level are also reported and referred to as peak minute ventilation, peak ventilatory equivalent for oxygen, and peak ventilatory equivalent for carbon dioxide, respectively. Blood pressure was measured by auscultation in the sitting position before the start of exercise. Heart rate was derived from the electrocardiogram at the end of the sitting rest period and throughout the exercise test. Heart rate immediately before termination of the exercise test is reported as peak heart rate. The patients were asked to rate their feeling of exertion at the end of exercise on a scale from 6 to 20 (Borg score).

\section{CARDIAC CATHETERISATION}

Eighty six patients $(77 \%$ of the study population) underwent an invasive haemodynamic evaluation in the supine position, after an overnight fast, within a median time of two days from the exercise test (range 0 to 36 days). Cardiac output was measured by the thermodilution method in 79 patients (12 in atrial fibrillation, 67 in sinus rhythm), and by the direct oxygen Fick method in seven (three in atrial fibrillation, four in sinus rhythm). Cardiac index was calculated as cardiac output divided by body surface area; stroke volume (index) was obtained by dividing cardiac output (index) by heart rate.

\section{RADIONUCLIDE ANGIOGRAPHY}

Ninety four patients ( $85 \%)$ underwent equilibrium gated radionuclide angiography at supine rest to assess left ventricular function. The investigation took place within a median time of two days from the exercise test (range 0 to 22 days).

The blood pool of the patient was labelled with technetium- $99 \mathrm{~m}$, and the change of shape of the blood pool within the left ventricle was followed with a gamma camera. Radionuclide activity was collected synchronously with the $\mathrm{R}$ wave of the electrocardiogram. The RR interval was divided in time frames. During several hundreds of heart beats the radionuclide counts were stored in the memory of the computer in the respective time frames, and the respective frames were summed.

To handle irregularly varying cardiac cycle lengths, in all patients - whether or not in atrial fibrillation-a "window" was determined before recordings of ventricular activity were started. The window comprised the mean of 10 consecutive RR intervals plus and minus $10 \%$ of this mean, but was adapted by the computer program throughout the investigation to account for changes in heart rate. Data acquisition was performed during 600 seconds (10 minutes), where count number and time only proceeded for cardiac cycles falling within the determined window. Thus in patients with an irregular heart rhythm, more RR intervals were rejected by the computer, and the investigation time was prolonged so as to obtain reliable estimations of ventricular function in such patients as well.

\section{STATISTICAL ANALYSIS}

SAS software (SAS Institute Inc, Cary, NC, USA) was used for the statistical analysis. Values are reported as mean (SD). Patients in sinus rhythm were compared to patients in atrial fibrillation with unpaired Student $t$ tests in the case of continuous variables. For categorical variables, comparisons were performed by either Fisher's exact tests (when dealing with small frequencies) or $\chi^{2}$ analysis. 
Table 1 General characteristics of the study population: male chronic heart failure patients

\begin{tabular}{|c|c|c|c|c|}
\hline & \multicolumn{2}{|c|}{ Patients in sinus rhythm } & \multicolumn{2}{|c|}{ Patients in atrial fibrillation } \\
\hline Number & 93 & & 18 & \\
\hline Age (years; mean (SD)) & 50 & (10) & 53 & (11) \\
\hline Weight (kg; mean (SD)) & 74 & (11) & 74 & (12) \\
\hline Height $(\mathrm{cm}$; mean $(\mathrm{SD}))$ & 173 & (6) & 172 & (6) \\
\hline $\mathrm{BMI}\left(\mathrm{kg} / \mathrm{m}^{2} ;\right.$ mean $\left.(\mathrm{SD})\right)$ & 24.6 & $(3.5)$ & 24.9 & $(3.4)$ \\
\hline $\mathrm{BSA}\left(\mathrm{m}^{2} ;\right.$ mean $\left.(\mathrm{SD})\right)$ & 1.8 & $(0.14)$ & 1.8 & $(0.15)$ \\
\hline \multicolumn{5}{|c|}{ Aetiology of heart failure (n (\%)) } \\
\hline Idiopathic CMP & 51 & (55) & 9 & $(50)$ \\
\hline Ischaemic heart disease & 37 & $(40)$ & 6 & (33) \\
\hline Miscellaneous & 5 & (5) & 3 & (17) \\
\hline \multicolumn{5}{|l|}{ Medication (n (\%)) } \\
\hline ACE inhibitors & 79 & $(85)$ & 14 & $(78)$ \\
\hline Diuretics & 71 & (76) & 17 & (94) \\
\hline Digitalis & 62 & (67) & 16 & (89) \\
\hline Anticoagulants & 55 & (59) & 13 & $(72)$ \\
\hline$\beta$ Blockers & 14 & (15) & 2 & (12) \\
\hline
\end{tabular}

BMI, body mass index; BSA, body surface area; CMP, cardiomyopathy; ACE, angiotensin converting enzyme.

Table 2 Cardiac catheterisation and equilibrium gated radionuclide angiography: data at supine rest in male chronic heart failure patients

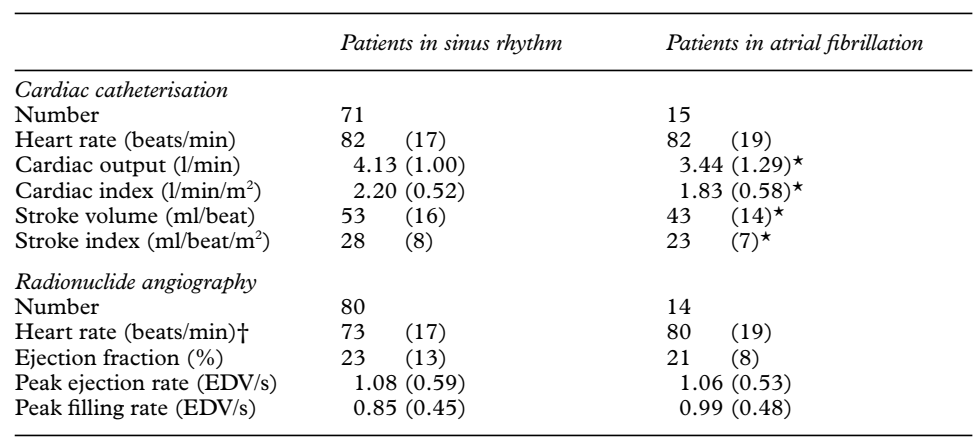

Values are mean (SD).

${ }^{*} \mathrm{p}<0.05$; patients in atrial fibrillation $v$ patients in sinus rhythm, unpaired Student $t$ test.

tThe heart rate is based on cardiac cycles with a duration not exceeding the window (see Methods).

EDV, end diastolic volume.
HAEMODYNAMIC DATA AND LEFT VENTRICULAR FUNCTION AT REST

Heart rate at supine rest-both during catheterisation and radionuclide angiography — was not significantly different between patients in atrial fibrillation and the others (table 2). However, catheterisation showed that cardiac output and stroke volume were lower in atrial fibrillation ( $\mathrm{p}<0.05)$; this difference persisted after normalisation for body size. Left ventricular function-quantified by radionuclide ejection fraction, peak ejection rate, and peak filling rate-was similar in the two groups.

\section{EXERCISE TESTING}

Heart rate at sitting rest was higher in the patients with atrial fibrillation than in the patients with sinus rhythm, at 93 (16) $v$ 84 (16) beats/min $(\mathrm{p}<0.05)$, whereas blood pressure did not differ significantly between patients in atrial fibrillation and patients in sinus rhythm (111 (19)/73 (11) mm Hg and 117 (21)/77 (12) mm Hg, respectively). Peak $\mathrm{VO}_{2}$ averaged $1231(460) \mathrm{ml} / \mathrm{min}$ or 16.6 (5.4) $\mathrm{ml} / \mathrm{kg} / \mathrm{min}$ in the total study population; the highest work load that could be sustained for one minute amounted to 95 (36) W. Results at peak exercise in the two groups are given in fig 1 . In the group of patients with atrial fibrillation, exercise tolerance was approximately $20 \%$ lower than in the patients with sinus rhythm. Peak $\dot{\mathrm{VO}}_{2}$ averaged 1021 (309) $\mathrm{ml} / \mathrm{min}$ or $13.8(3.6) \mathrm{ml} / \mathrm{kg} / \mathrm{min}$, and $1271(475) \mathrm{ml} / \mathrm{min}$ or $17.1(5.6) \mathrm{ml} / \mathrm{kg} /$ min $(\mathrm{p}<0.01)$, respectively; the highest work load that could be sustained for one minute amounted to $78(27) \mathrm{W}$ and $98(36) \mathrm{W}$ $(\mathrm{p}<0.05)$. Peak heart rate was higher in the patients with atrial fibrillation $(\mathrm{p}<0.05)$, whereas peak respiratory gas exchange ratio and Borg score (16.2 (1.5) in atrial fibrillation and 15.9 (1.7) in sinus rhythm) were similar in the two groups. Peak oxygen pulse, whether or not corrected for body surface area, was significantly higher in the patients with sinus rhythm (4.91 (1.46) v $3.55(0.74) \mathrm{ml} / \mathrm{beat} / \mathrm{m}^{2}$; $\mathrm{p}<0.001)$. Peak ventilatory equivalent for carbon dioxide (41 (9) $v 47$ (14)) and peak ventilatory equivalent for oxygen (45 (11) $v$ 51 (16)) tended to be lower in sinus rhythm ( $\mathrm{p}=0.08$ and $\mathrm{p}=0.11$, respectively).

tics did not differ between the two gro (table 1). Either idiopathic cardiomyopathy or ischaemic heart disease was diagnosed in the majority of the patients. In the others, chronic heart failure was ascribed to hypertension $(\mathrm{n}=1)$, a traumatic myocardial infarction $(\mathrm{n}=1)$, haemochromatosis $(\mathrm{n}=1),{ }^{19}$ alcohol abuse $(n=1)$, or a combination of causes $(n=4)$. Estimated duration of chronic heart failure, as judged from the onset of typical symptoms (dyspnoea, fatigue), hospital admissions or both, was similar in patients with atrial fibrillation and patients with sinus rhythm: median 18.6 months (range 1 to 96 months), and 12.0 months (range 0.5 to 228 months), respectively. There were no significant differences with respect to drug intake between both groups, but digitalis tended to be more frequently prescribed for patients in atrial fibrillation ( $\mathrm{p}=0.06)$.

\section{Discussion}

Exercise intolerance is an important consequence of chronic heart failure. Peak $\mathbf{V O}_{2}$ in the study averaged $16.6 \mathrm{ml} / \mathrm{kg} / \mathrm{min}$, which is about $60 \%$ of what would be expected according to age and body size. ${ }^{20}$ Moreover, exercise intolerance was still more pronounced in the presence of atrial fibrillation. Both peak $\mathrm{VO}_{2}$ and peak work load were approximately $20 \%$ lower in the patients with atrial fibrillation than in those in sinus rhythm. Nevertheless, peak respiratory gas exchange ratios and Borg scores were almost identical in the two groups, suggesting that the patients on both groups gave a good and similar effort. Further, both groups were highly comparable with respect to their general 111 heart transplant candidates of the present 

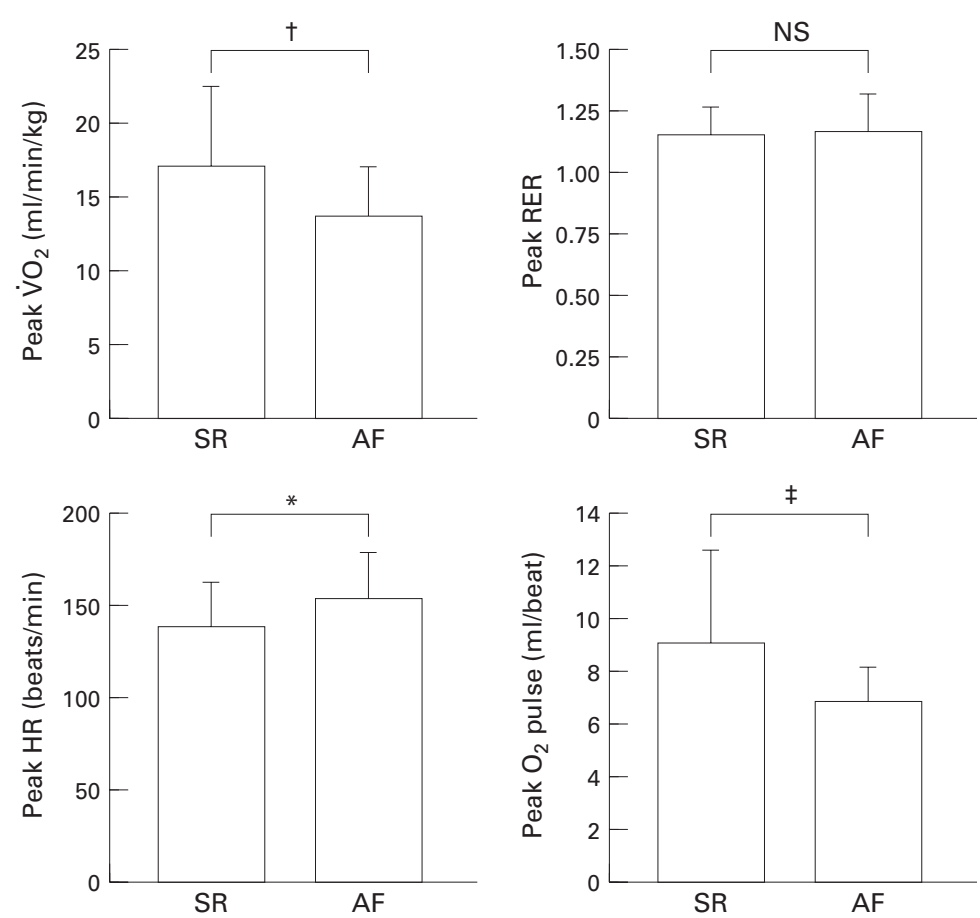

Figure 1 Peak oxygen uptake $\left(\dot{V}_{2}\right)$, peak respiratory gas exchange ratio ) RER), peak heart rate (HR), and peak oxygen pulse $\left(\mathrm{O}_{2}\right.$ pulse) in chronic heart failure patients in sinus rhythm (SR) and atrial fibrillation $(A F)$. Data are mean $(S D) ;{ }^{*} p<0.05 ; t p<0.01$; $\ddagger p<0.001$.

characteristics - that is, age, body size, chronic heart failure aetiology, and drug intakeexcept perhaps for the use of digitalis.

Our cross sectional findings are in agreement with studies in which the exercise capacity of patients in atrial fibrillation improved after successful cardioversion. ${ }^{24-9}$ However, patients with advanced chronic heart failure were either excluded or poorly represented in those reports, which mainly involved patients with mild cardiac dysfunction and mild exercise intolerance, predominantly New York Heart Association class I or II patients. To the best of our knowledge, only one report-that is, the multicentre vasodilator in heart failure trials $(\mathrm{V}-\mathrm{HeFT} \text { I and II })^{10}$ - has been published on patients with worse cardiac and clinical status, mainly New York Heart Association class II and III. Their peak $\dot{\mathrm{VO}}_{2}$ was substantially lower than in the above mentioned reports. In V-HeFT I, peak $\mathrm{VO}_{2}$ in patients in atrial fibrillation $(\mathrm{n}=99)$ was $5.4 \%$ but not significantly $(\mathrm{p}=0.08)$ lower than in the patients in sinus rhythm $(n=533)$, and exercise duration was identical in both groups. The V-HeFT II data showed that peak $\dot{\mathrm{VO}}_{2}$ was only $0.7 \%$ lower $(\mathrm{p}=0.66)$ in the patients with atrial fibrillation $(\mathrm{n}=107)$ than in the patients in sinus rhythm $(\mathrm{n}=688)$; exercise duration was also very similar in the two groups. However, the authors did not account for characteristics that were significantly different between patients with atrial fibrillation and patients in sinus rhythm, such as age, aetiology of chronic heart failure, left ventricular ejection fraction, and medication. Thus the V-HeFT findings disagree with the results of the cardioversion studies and with the present analysis. Discrepancies may be due to differences regarding study design, selection criteria, and clinical status or age of the patients.

We hypothesised that the presence of atrial fibrillation would impair the cardiac output response to exercise, and consequently reduce the patients' exercise tolerance. Although several investigators have shown that peak $\dot{\mathrm{VO}}_{2}$ is essentially unrelated to resting cardiac output in chronic heart failure, it has been found that the relation of peak $\mathrm{VO}_{2}$ to peak exercise cardiac output is much stronger, and usually significant. ${ }^{21-23}$ Our analysis shows that stroke volume and cardiac output are indeed lower at rest in patients with atrial fibrillation, but haemodynamic variables were not measured during exercise in the pretransplant screening protocol. We did find, however, that the peak oxygen pulse-that is, a crude non-invasive measure of stroke volume at peak effort - was significantly lower in atrial fibrillation. This variable has also been shown to increase significantly after successful cardioversion, together with peak $\mathrm{VO}_{2}{ }^{2}{ }^{46}$ The higher peak heart rate we observed is a common finding in patients with atrial fibrillation, and is generally regarded as a compensatory mechanism for a lower stroke volume. ${ }^{2-10}$

There are several mechanisms by which the presence of atrial fibrillation may adversely affect cardiac output. The arrhythmia is characterised by totally disorganised atrial depolarisations without effective atrial contraction. ${ }^{24}$ At rest, the atrial kick to left ventricular filling has been shown to be important in maintaining cardiac output, ${ }^{14}$ but its importance may decline with age ${ }^{11}$ or with higher left ventricular filling pressures, or both. ${ }^{12}$ Further, the contribution of the atrial kick may change during exercise. Most, ${ }^{13}{ }^{14} 25$ but not all, ${ }^{26}$ studies in patients with artificial pacemakers suggest that the increase in ventricular rate during exercise is more important to cardiac output than atrial contraction, and this may be particularly true for patients with systolic left ventricular dysfunction. ${ }^{27}$ On the other hand, restoration of atrial contraction has also been shown to parallel ${ }^{5}$ or to precede ${ }^{6}$ the improvement of peak $\mathrm{VO}_{2}$ after cardioversion; the lower peak heart rate after cardioversion suggests that intact atrial functioning yields a higher stroke volume during exercise, and thus increases exercise capacity. The irregularity of the ventricular response in atrial fibrillation is another mechanism for haemodynamic impairment. It has been shown in the resting dog that an irregular ventricular rhythm is associated with a $9 \%$ decline in cardiac output compared with a regular ventricular rhythm at the same average pacing rate. ${ }^{15}$

The patients with atrial fibrillation in the present study might have had a lower exercise capacity because they had had chronic heart failure for a longer time, or because they had worse cardiac function. However, the duration of chronic heart failure was similar in the two groups, and-compared to the patients in sinus rhythm - those in atrial fibrillation showed no worse left ventricular function on radionuclide angiography. The latter technique might be less 
valid in patients with atrial fibrillation, but in the present study only cardiac cycles with a certain duration were taken into account and longer acquisition times were applied if required. Further, as we assessed ventricular function only at rest, we cannot exclude the possibility that ventricular function changed differentially in the two groups during exercise.

It is unlikely that differences in exercise tolerance between the patients in atrial fibrillation and those in sinus rhythm are due to drug intake-statistical analysis did not reveal significant differences. Only digoxin tended to be used more often in patients with atrial fibrillation, but this cannot explain the difference in exercise tolerance. The ability of digitalis glycosides to improve exercise capacity in patients with chronic heart failure remains controversial. ${ }^{28-32}$

In summary, we have shown that there is a lower peak $\dot{\mathrm{VO}}$, in heart transplant candidates with atrial fibrillation than in those in sinus rhythm. There are several mechanisms by which loss of the atrial function may aggravate exercise intolerance in chronic heart failure, but these are poorly understood and should be addressed in future investigations. Nevertheless, this analysis may highlight two facts. First, even in severe chronic heart failure, the presence of atrial fibrillation should be considered when studying exercise related phenomena-whether or not patients were in atrial fibrillation has often not been reported. Second, the presence or absence of atrial fibrillation in heart transplant candidates may need to be considered when interpreting peak $\dot{\mathrm{VO}}_{2}$ as a prognostic index. In the setting of chronic heart failure, the presence of atrial fibrillation may not mean a worse outcome per se, ${ }^{10}$ but it may reduce exercise tolerance.

We thank Professor L Mortelmans and Dr A Maes from the department of nuclear cardiology for their kind collaboration. department of nuclear cardiology for their kind collaboration. acknowledged. RF is holder of the Prof A Amery Chair in acknowledged. RF is holder of the Prof A Amery Chair in Hypertension
(Belgium)

1 Prystowsky EN, Benson DW, Fuster V, Hart RG, Kay GN, Myerburg RJ, et al. Management of patients with atrial fibrillation. A statement for healthcare professionals from
the Subcommittee on Electrocardiography and Electro-
physiology, American Heart Association. Circulation physiology, American

2 Ueshima K, Myers J, Morris CK, Atwood JE, Kawaguchi T, Froelicher VF. The effect of cardioversion on exercise capacity in patients with atrial fibrillation. Am Heart $\mathcal{F}$ 1993;126:1021-4.

3 Ueshima K, Myers J, Graettinger WF, Atwood JE, Morris $\mathrm{CK}$, Kawaguchi $\mathrm{T}$, et al. Exercise and morphologic comparison of chronic atrial fibrillation and normal sinus rhythm. Am Heart f 1993;126:260-1.

4 Atwood JE, Myers J, Sullivan M, Forbes S, Sandhu S, Callaham $\mathrm{P}$, et al. The effect of cardioversion on maximal exercise capacity in patients with chronic atrial fibrillation. $\mathrm{Am}$ Heart $\mathcal{f} 1989 ; 118: 913-8$.

5 Lipkin DP, Frenneaux M, Stewart R, Joshi J, Lowe T, McKenna WJ. Delayed improvement in exercise capacity after
cardioversion of atrial fibrillation to sinus rhythm. Br Heart cardioversion of a

6 Van Gelder IC, Crijns HJGM, Blanksma PK, Landsman MLJ, Posma JL, Van Den Berg MP, et al. Time course of hemodynamic changes and improvement of exercise tolerance after cardioversion of chronic atrial fibrillation unassociated with cardiac valve disease. Am 7 Cardiol 1993 72:560-6.

7 Gosselink ATM, Bijlsma EB, Landsman MLJ, Crijns HJGM, Lie KI. Long-term effect of cardioversion on peak oxygen consumption in chronic atrial fibrillation: a 2-year follow-up. Eur Heart f 1994;15:1368-72.
8 Gosselink ATM, Crijns HJGM, Van Den Berg MP, Van Den Broek SAJ, Hillege H, Landsman MLJ, et al. Functional capacity before and after cardioversion of atrial fibrillation: controlled study. Br Heart $\mathcal{F}$ 1994;72:161-6.

9 Lundström T, Karlsson Ö. Improved ventilatory response to exercise after cardioversion of chronic atrial fibrillation to sinus rhythm. Chest 1992;102:1017-22.

10 Carson PE, Johnson GR, Dunkman WB, Fletcher RD, Farrell L, Cohn JN. The influence of atrial fibrillation on prognosis in mild to moderate heart failure: the V-HeFT studies. Circulation 1993;87(suppl VI):VI102-10.

11 Miyatake K, Okamoto M, Kinoshita N, Owa M, Nakasone I, Sakakibara $\mathrm{H}$, et al. Augmentation of atrial contribution to left ventricular inflow with aging as assessed by intracardiac Doppler flowmetry. Am f Cardiol 1984;53:586-9.

12 Greenberg B, Chatterjee K, Parmley WW, Werner JA, Holly AN. The influence of left ventricular filling pressure on atrial contribution to cardiac output. Am Heart f 1979;98: $742-51$.

13 Linde-Edelstam CM, Juhlin-Dannfelt A, Nordlander R, Pehrsson KS. The hemodynamic importance of atrial systole: a function of the kinetic energy of blood flow? PACE 1992;15:1740-9.

14 Kristensson B-E, Arnman K, Rydén L. The haemodynamic importance of atrioventricular synchrony and rate increase at rest and during exercise. Eur Heart f 1985;6:773-8.

15 Naito M, David D, Michelson EL, Schaffenburg M, Dreifus LS. The hemodynamic consequences of cardiac arrhythmias: evaluation of the relative roles of abnormal atrioventricular sequencing, irregularity of ventricular rhythm and atrial fibrillation in a canine model. Am Heart $\mathcal{f}$ rhythm and atrial fibr

16 Stelken AM, Younis LT, Jennison SH, Miller DD, Miller LW, Shaw LJ, et al. Prognostic value of cardiopulmonary exercise testing using percent achieved of predicted peak oxygen uptake for patients with ischemic and dilated cardiomyopathy. F Am Coll Cardiol 1996;27:345-52.

17 Haskell WL, Leon AS, Caspersen CJ, Froelicher VF, Hagberg JM, Harlan W, et al. Cardiovascular benefits and assessment of physical activity and physical fitness in adults. Med Sci Sports Exerc 1992;24(suppl):S201-20.

18 Hanson P. Exercise testing and training in patients with chronic heart failure. Med Sci Sports Exerc 1994;26:527-37.

19 Porter J, Cary N, Schofield P. Haemochromatosis presenting as congestive cardiac failure. Br Heart f 1995;73:73-5.

20 Jones NL. Clinical exercise testing, 3rd ed. Philadelphia: WB Saunders, 1988:165-71.

21 Metra M, Dei Cas L, Panina G, Visioli O. Exercise hyperventilation chronic congestive heart failure, and its relation to functional capacity and hemodynamics. $A m \mathcal{F}$ Cardiol 1992;70:622-8.

22 Volterrani M, Clark AL, Ludman PF, Swan JW, Adamopoulos S, Piepoli M, et al. Predictors of exercise capacity in chronic heart failure. Eur Heart f 1994;15:801-9.

23 Franciosa JA, Baker BJ, Seth L. Pulmonary versus systemic hemodynamics in determining exercise capacity of patients with chronic left ventricular failure. Am Heart f 1985;110: $807-13$

24 Zipes DP. Atrial fibrillation. In: Braunwald E, ed. Heart disease: a textbook of cardiovascular medicine, 3rd ed. Philadelphia: WB Saunders, 1988:672-4.

25 Pehrsson SK. Influence of heart rate and atrioventricular synchronization on maximal work tolerance in patients treated with artificial pacemakers. Acta Med Scand 1983;214:311-15.

26 Lemke B, Dryander SV, Jäger D, Machraoui A, MacCarter $\mathrm{D}$, Barmeyer J. Aerobic capacity in rate modulated pacing. PACE 1992;15:1914-18.

27 Frielingsdorf J, Dür P, Gerber AE, Vuilliomenet A, Bertel O. Physical work capacity with rate responsive ventricular pacing (VVIR) versus dual chamber pacing (DDD) in patients with normal and diminished left ventricular function. Int f Cardiol 1995;49:239-48.

28 Sullivan M, Atwood JE, Myers J, Feuer J, Hall P, Kellerman $\mathrm{B}$, et al. Increased exercise capacity after digoxin administration in patients with heart failure. $7 \mathrm{Am}$ Coll Cardiol 1989;13:1138-43.

29 Fleg JL, Rothfeld B, Gottlieb SH, Wright J. Effect of maintenance digoxin therapy on aerobic performance and exercise left ventricular function in mild to moderate heart failure due to coronary artery disease: a randomized, placebocontrolled, crossover trial. f Am Coll Cardiol 1991;17:74351 .

30 Uretsky BF, Young JB, Shahidi FE, Yellen LG, Harrison MC, Jolly MK. Randomized study assessing the effect of digoxin withdrawal in patients with mild to moderate chronic congestive heart failure: results of the PROVED

31 Tanabe Y, Takahashi M, Momotsu T, Kuwano H, Kodama $\mathrm{M}$, Tsuda $\mathrm{T}$, et al. Effect of digoxin on exercise performance in mildly symptomatic patients with idiopathic dilated cardiomyopathy and sinus rhythm. $f_{p n}$ Heart F 1994;35:301-10.

32 Morisco C, Cuocolo A, Romano M, Nappi A, Iaccarino G, Volpe $\mathrm{M}$, et al. Influence of digitalis on left ventricular functional response to exercise in congestive heart failure. Am f Cardiol 1996;77:480-5. 